\title{
THE STUDY OF INFLUENCE OF THE PROCESS OF MECHANICAL ADDITIONAL CLEANING ON THE SURFACE ONION LAYER AT COMBINED PROCESS OF CLEANING
}

\author{
Oleg Tereshkin \\ Department of Hotel and Restaurant Business \\ Kharkiv State University of Food Technology and Trade \\ 333 Klochkovska str., Kharkiv, Ukraine, 61051 \\ tereshkin09@mail.ru \\ Dmytro Horielkov \\ Department of Equipment for Food and Hospitality Industry named after M. I. Belyaeva \\ Kharkiv State University of Food Technology and Trade \\ 333 Klochkovska str., Kharkiv, Ukraine, 61051 \\ gorelkov.dmv@gmail.com \\ Dmytro Dmytrevskyi \\ Department of Equipment for Food and Hospitality Industry named after M. I. Belyaeva \\ Kharkiv State University of Food Technology and Trade \\ 333 Klochkovska str., Kharkiv, Ukraine, 61051 \\ dmitrevskyidv@gmail.com,dmitrevskyi@mail.ru \\ Vitalii Chervonyi \\ Department of Equipment for Food and Hospitality Industry named after M. I. Belyaeva \\ Kharkiv State University of Food Technology and Trade \\ 333 Klochkovska str., Kharkiv, Ukraine, 61051 \\ chervonyi.v@gmail.com
}

\begin{abstract}
The one of the ways of solving question of high-quality cleaning of vegetables is the use of combined methods of cleaning, their study and creation of equipment. The improvement of process for its realization and equipment support at trade enterprises, restaurant economy and mini-factories is a topical task. The expedience of elaboration and introduction of combined processes and equipment for their realization at institutions of the restaurant economy and vegetable-processing enterprises give a possibility to exclude the additional equipment for calibration, sorting, washing, additional cleaning. It, in its turn, will provide the safety at production, favoring the more rational use of resources.

The one of most prospective directions of intensification of process of cleaning of the vegetable raw material is an elaboration of combined methods and new specialized apparatuses, which work principle is based on combination of the processes of cleaning of product.

The experimental setting was elaborated with correspondent methodology that allows carry out the study of process of cleaning of onion with possible determination of influence of all its parameters on the percent of the raw material losses and effectiveness of product cleaning. It is provided due to the presence of work drum in experimental setting that rotates around its axis. The rotation frequency can be changed within the necessary diapason. The work drum has on its surface the special orifices for cutting off the inedible part of onion. The experimental setting also includes tensometric module that allows determine the effort of separation of peel from onion.

The use of apparatus for cleaning of onion will give a possibility to intensify process, to improve the quality of cleaning, to decrease the percent of raw material losses.

Keywords: onion, combined influence on the raw material, cleaning parameters, preliminary boiling, mechanical additional cleaning.

DOI: $10.21303 / 2504-5695.2016 .00239$

(C) Oleg Tereshkin, Dmytro Horielkov, Dmytro Dmytrevskyi, Vitalii Chervonyi
\end{abstract}

\section{Introduction}

The prospective direction of intensification and mechanization of onion cleaning is the elaboration of new apparatuses, which action principles is based on combination of thermal and 
mechanical impact on the product $[1,2]$. Realization of innovative combined cleaning methods is complicated with absence of complex researches in this direction in Ukraine in whole, especially information about typical structural-mechanical, physical-mechanical and thermophysical properties of the vegetable raw material, methods and experimental settings for determination of their influence on the parameters of processes [3].

It is economically expedient to use universal and multi-operational compact equipment that realizes several processes that will allow exclude the additional equipment, essentially shorten the losses of different types of raw material and produce the goods of high quality $[4,5]$.

Elaboration and introduction into serial production of eco-friendly resource-reserving equipment of the new generation that realizes principally new combined methods of complex processing of agricultural raw material, competitive on Ukrainian internal market and foreign ones is a topical task $[6,7]$.

The one of the variants of solving question of high-quality onion cleaning is the elaboration of method of its cleaning and creation of modern equipment for its realization [8, 9]. For intensification of elaboration of new equipment it is necessary to carry out the series of theoretical and experimental researches that will determine the influence of parameters of cleaning process on the percent of raw material losses and quality of product cleaning. In elaborated combined cleaning method the final stage of onion processing is a process of its mechanical cleaning [10]. For the study of this process, the series of experiment is necessary to determine its most rational mode.

\section{Materials and Methods}

It is well-known, that onions can significantly differ by geometric sizes. At thermal processing by steam the value of thermal flow for area unit in onion with more geometric sizes can be less comparing with onion of less size at equal parameters of processing. That is why at studies the onions were divided in three fractions by sizes. The onions of first fraction had weight up to $50 \mathrm{~g}$, of the second one - from 50 to $120 \mathrm{~g}$, third - more than $120 \mathrm{~g}$. The onions were also divided by the ripening term: fast-ripening, middle-ripening and late. Along with it the onions were divided by the content of dry substances: spicy varieties that contain more than $15 \%$ of dry substances were related to the first group, semi-spicy with dry substances content from 12 to $15 \%$ - to the second one and sweat varieties with moisture content up to $12 \%$ - to the third.

At the beginning of research the onion was processed by steam in the work chamber of experimental setting for the study of influence of thermal processing on surface layer of onion [11]. The onion, preliminary processed by steam with temperature $105 \ldots 110{ }^{\circ} \mathrm{C}$, pressure $1,1 \ldots 1,4 \mathrm{~atm}$. (Fig. 1, a) was put in drum, the speed regulator sets the rotation frequency of it. Experimental setting for the study of the process of onion cleaning includes experimental drum module, tensometric module, device of digital tensometric measuring DTM-1 (producer - RTC "LaborComplexService" (Russia)) and electronic weighs. The process of additional mechanical cleaning is carried out directly in the work drum. The measuring of effort of peel separation is realized on the device DTM-1. The percent of raw material losses was determined by weighing of onions consignment before the start of process of mechanical additional cleaning and after finishing it. The drum frequency slowly varies within $50 \ldots 1000 \mathrm{~min}^{-1}$. After establishing the rotation frequency the onion is processed within chamber during certain period of time. The duration of mechanical additional cleaning process changed in diapason $30 \ldots 110 \mathrm{~s}$ with interval $20 \mathrm{~s}$. After processing the onion is loaded to the container for cleaned raw material that is placed under the work drum of apparatus. The quality of cleaning is determined by area and quantity of peel remains. Along with it the separated peel and also the peel that passed through the drum circulation at the expense of influence of centrifugal force is taken from work chamber. After that the onions that were not fully cleaned are peeled and weighed together with other. The remained coat of onions is removed by the handmade additional cleaning. After that the complex parameter of cleaning quality that includes the parameter of quantity of removed coat, parameter of area of onion cleaning, quantity of peel that passed through the drum perforation is determined. The minimal necessary frequency of drum rotation that must provide the maximally possible passage of peel beyond the work chamber is determined by the quantity of peel, passed through the drum. Based on the complex parameter of quality of 
onion cleaning, we chose the rational parameters of process: frequency, time of preliminary steam processing, duration of processing. After that the series of rational experiments with stable indices of frequency and duration of processing was carried out by the change of geometric parameters of the drum for determination of rational size of orifices. On the Fig. $\mathbf{1}$ are presented the samples of onion that underwent preliminary steam processing and the ones that underwent the further additional mechanical cleaning.

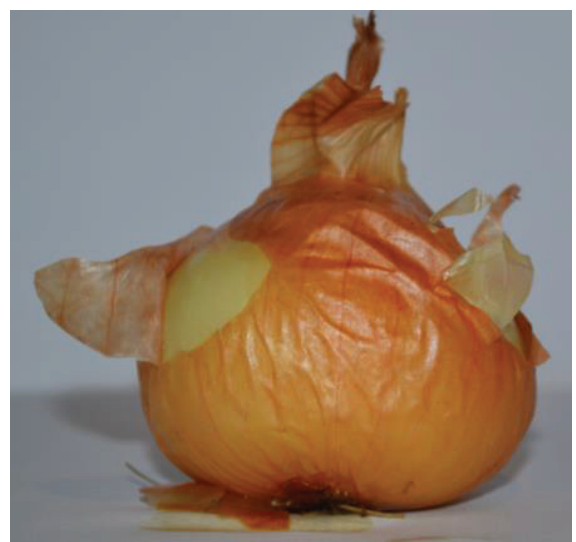

$a$

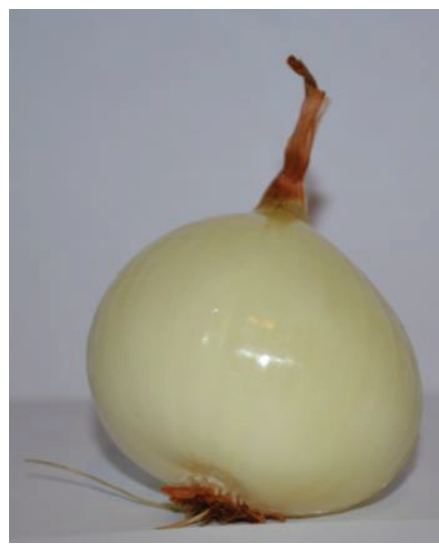

$b$

Fig. 1. Samples of onions at combined cleaning process: $a$ - after preliminary steam processing; $b$ - after further additional mechanical cleaning

The experimental setting, elaborated using this method allows carry out the study of the process of onion cleaning with possibility to take into account all external factors. The factors of subject are studied by the standard methods using thermogravimetry [12]. On the Fig. 2 is presented the general appearance of experimental drum module for the study of mechanical processing of onion.

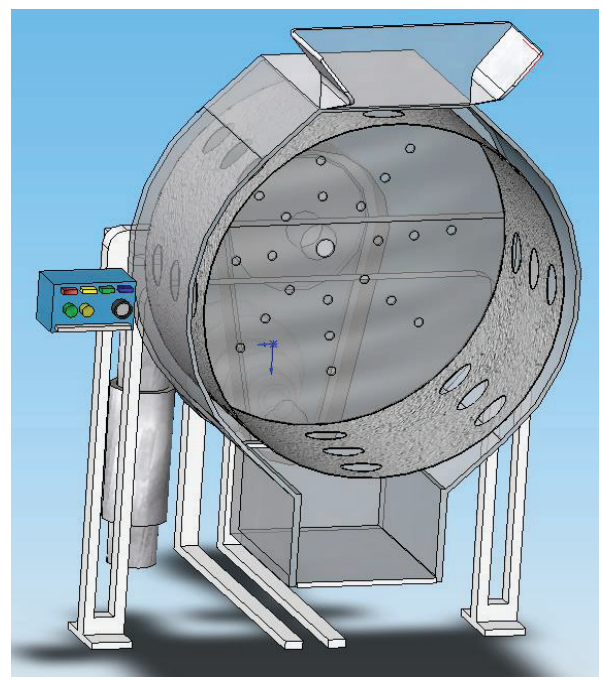

Fig. 2. The general appearance of experimental drum module for the study of mechanical processing of onion

As the quality parameters at experimental studies of process of mechanical additional cleaning were chosen the percent of cleaned onions and percent of raw material losses. It is necessary to establish the dependence of percent of cleaned onions and percent of raw material losses on the penetration depth of their surface layer. 
At the study for determination of percent of cleaned onions, the samples, which effort of peel separation was in diapason from 1,142 $\mathrm{N}$ to $15,0 \mathrm{~N}$ were chosen. The onion with more effort of peel separation was not chosen, because at the process of additional mechanical cleaning its peel was not fully removed. The duration of process of additional mechanical cleaning changed in diapason $30 . .110 \mathrm{~s}$ with interval $20 \mathrm{~s}$.

The thermal processing depth of surface layer was chosen as the parameter that influences the percent of raw material loss. To decrease the percent of raw material losses at mechanical additional cleaning it is necessary to minimize the depth of its steam thermal processing. But when the onions have significant mechanical and biological defects, there is a need in increase of thermal processing depth to remove the inedible part of product. That is why to study the process of mechanical additional cleaning as to determination of percent of the raw material losses, the samples, which thermal processing depth was from 1 to $5 \mathrm{~mm}$ were selected.

On the Fig. 3 is presented the experimental setting for the measuring of separation of peel from onion.

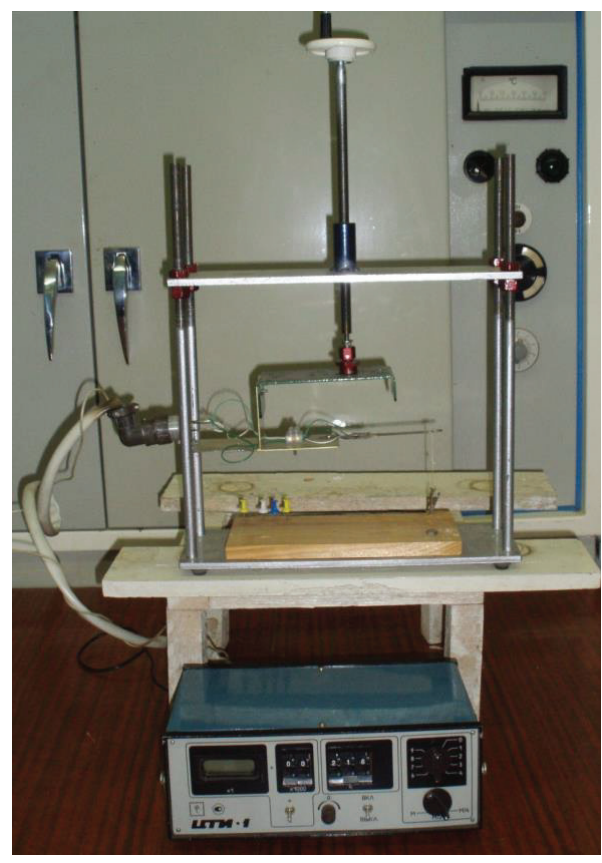

Fig. 3. General appearance of tensometric module and device DTM-1 for the measuring of separation of peel from onion

The scheme of tensometric module and device DTM-1, produced by RTC "LaborComplexService" (Russia) is presented on the Fig. 4. The setting consists of the following elements. The low 1 and top 8 supports are for fixation of elements. The supports are fixed on stands 3 . Regulation of height of the top support is realized by fixing nuts 10 . The directive bush 8 is fixed to the top support; in the middle of the bush is the orifice with screw-thread that the pivot 12 is screwed in. The screw-thread is cut on whole its length and it rotates by rotation handle 9, fixed on the top of pivot. On the low tip of pivot is fixed the hinge 5, joined to L-like plate 2. In the middle of hinge are the rolling bearings that provide the vertical movement of hinge and L-like plate at pivot rotation. The thin flexible plate 6 is connected to L-like plate. The strain sensors of resistance 7 are fixed on this plate. To provide the continuity of connection between strain sensors and digital measurer DTM-1 the dielectric isolator 13 is fixed. The fixer 15 of the onion sample 18 is set on flexible plate. In the middle of fixer is the length regulator 16, using which it raises or goes down depending on geometric sizes of onion sample. After fixation of onion experimental sample on fixer it is squeezed from two sizes by the special squeezers 4, and onion peel is fixed by squeezer 17. Experimental setting for the study of effort of onion peel removal functions as following. The onion is squeezed from both sides 
by the squeezers 4 , placed on support 1 . The onion peel is incised and fixed by squeezed 17 , placed on the one tip of fixer. The other tip of fixer is connected to the length regulator 16.

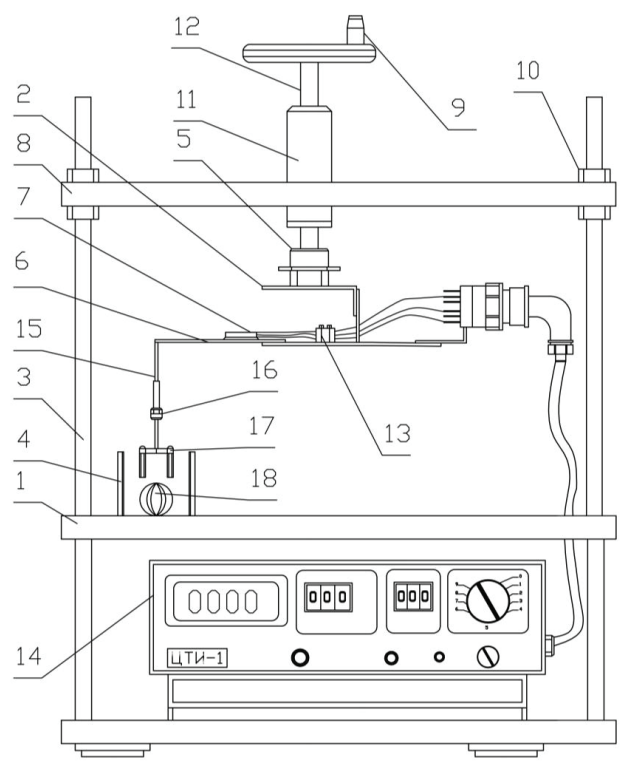

Fig. 4. The scheme of tensometric module and device DTM -1 for the study of effort of onion peel removal: 1 - low support of setting; 2 - L-like plate; 3 -stand; 4 - squeezers of onion experimental sample; 5 - hinge; 6 - flexible plate; 7 - strain sensors of resistance; 8 - top support of setting; 9 - rotation handle; 10 - fixing nuts of top support; 11 - directive bush; 12 - pivot;

13 - dielectric isolator; 14 - digital tensometric measurer DTM-1; 15 - fixer of onion experimental sample; 16 - regulator of fixer movement; 17 - squeezers for fixation of onion peel; 18 - experimental onion sample

At rotation of handle 9 the pivot 12 also rotates, lifting L-like plate 2 that, in its turn, lifts the flexible plate 6 and fixer 15 with onion experimental sample 18. At that the flexible plate 6 is bent, because it is raised on the one side together with L-like plate and on the other one is hold by the onion experimental sample 18, squeezed by two squeezers 4 . The resistance of strain sensors 7 changes at bending of flexible plate 6 .

As the result of effect of excessive steam pressure on the onion surface layer, the connection between peel and onion is broken, and at the lift of studied sample together with fixer, the removal of onion peel takes place. At the moment, when peel is separated from the onion, the maximal value of resistance bridge split is registered. At the same time the maximal value of resistance bridge split is fixed on electronic board of device DTM-1. After the peel removal, plate returns to the initial position. It must be noted, that the strain sensors are placed on both sides of plate and work for the different types of loading. The top strain sensor works for compression, the low one - for distension. These strain sensors are included to the united semi-bridge system, so the maximal split of system takes place and significant raise of its sensitivity is provided. That, in its turn, allows raise the exactness of measurements. The limits of measuring of device effort are $0 . .735 \mathrm{mN}$. The value of the dial scale division is $10 \mathrm{mN}$.

For the study of combined process of onion peeling the series of interconnected experiments was carried out. The urgent task was the determination of optimal geometric parameters of orifices of work drum and procedural parameters- duration of preliminary thermal processing by steam, frequency of drum rotation, duration of cleaning. The experiments were carried out for 3 coefficients of drum loading $\left(\mathrm{C}_{3}\right)$. It must be noted, that $\mathrm{C}_{3}=0,3$ was included in experiment because of practical aspect, because technological process at enterprises of restaurant economy does not always need the maximal loading of apparatus. In general the experiment was carried out for $\mathrm{C}_{3}=0,3$; $\mathrm{C}_{3}=0,5 ; \mathrm{C}_{3}=0,7$. Based on expedience of production and effectiveness of the work of apparatus, the 
two forms of drum orifices were chosen as initial experimental parameters: circle and ellipse. Geometrical sizes of the drum orifices within $12 . .22 \mathrm{~mm}$ were chosen based on minimal and maximal sizes of bottom and neck of onion of different varieties and form.

Besides the orifices geometry it was necessary to determine the optimal duration of cleaning and preliminary thermal processing by steam at experiment. The preliminary studies established that at steam processing at temperature $100 \ldots 105^{\circ} \mathrm{C}$ the boiling of onion surface layer together with peel takes place. The boiling to the depth up to $4,0 \ldots 4,2 \mathrm{~mm}$ provides the boiling of onion top layer that must be removed depending on storage life and variety, because it has the lowered moisture and is useless. Thus, the fact of boiling of further useless surface layer is the positive phenomenon that satisfies the conditions of cleaning process. According to experimental data, the short-term steam processing of onion within $50 \ldots 60 \mathrm{~s}$ does not lead to the necessary steaming of dry peel and first layer of flesh. The further thermal processing, depending on time, increases the penetration thickness, but decreases the duration of processing. Under condition of increase of the depth of thermal processing of onion surface layer, the increase of raw material losses at its further cleaning is expected, because the onion surface layer that was changed under steam impact is removed.

The diapason of revolutions within $40 \ldots 150 \mathrm{~min}^{-1}$ at cleaning was chosen according to the results of preliminary studies [13]. The studies demonstrated that with increase of drum revolutions within $200 \ldots 300 \mathrm{~min}^{-1}$ the irreversible deformation of onion, cracking and destruction were observed. As far as the process can be divided in several stages (preliminary steaming, cut of bottom and neck, removal of peel from onion, removal of peel from work chamber), it is expedient to carry out the study of process of peeling just in offered diapason of revolutions. That is why the diapason of preliminary steaming at small revolutions was chosen as up to $50 \mathrm{~min}^{-1}$ and of peeling process up to $150 \mathrm{~min}^{-1}$.

Under condition of increase of the depth of thermal processing of onion surface layer, the raw material losses at its mechanical cleaning increased, because the onion surface layer, changed under steam impact, is separated together with peel. In this case it is necessary to decrease the thermal processing depth of onion, correcting the thermal processing duration. But in the case of decrease of this parameter the process of peel separation from onion takes place insufficiently effectively or does not take place at all.

\section{Results}

At the study the dependence of percent of raw material losses on the parameters of process was established. The depth of preliminary thermal processing is from 4,0 to 4,2 $\mathrm{mm}$. The boiling on the given depth provides the effective separation of peel from onion with minimal losses of product. It was proved, that the maximal value of onion cleaning degree at combined cleaning process is $88 \ldots 98 \%$. Coefficient of work drum loading is $0,3 \ldots 0,7$, that allows effectively use the apparatus at rerolling enterprises. The optimal value of rotation frequency of work drum by the index of quantity of removed parts of onion corresponds to the value from 100 to $150 \mathrm{~min}^{-1}$. At this value of frequency the irreversible deformation of onion is not observed and the effective cleaning of product takes place.

\section{Conclusions}

To minimize the raw material losses and synchronously improve the quality of onion surface cleaning, the necessary duration of its preliminary thermal processing was determined. The necessary value of effort of onion peeling that provides the high effectiveness of cleaning process was established.

The experimental setting with rotating drum as the work chamber was elaborated. Based on chosen parameters of process that must be studied, the methodology of research was elaborated.

The experimental setting, using the offered methodology, allows study the process of onion cleaning with a possibility to take into account all external factors such as rotation frequency of work drum and sizes of orifices. The value of effort of peeling was measured using tensometric module, included to experimental setting. The rational value of coefficient of drum loading was determined. The diapason of work drum revolutions was established. 
The experimental studies of influence of the process of additional mechanical cleaning on the onion surface layer gave a possibility to determine the parameters of combined cleaning process. The use of rational parameters of combined process of onion cleaning allows decrease the raw material losses, improve the quality of cleaning and significantly intensify and mechanize the cleaning process. In further the authors plan to use the elaborated methods for the study of combined process of cleaning of different types of vegetables. The presented researches can be also used at designing of new types of equipment.

\section{References}

[1] Juániz, I., Ludwig, I. A., Huarte, E., Pereira-Caro, G., Moreno-Rojas, J. M., Cid, C., De Peña, M.-P. (2016). Influence of heat treatment on antioxidant capacity and (poly)phenolic compounds of selected vegetables. Food Chemistry, 197, 466-473. doi: 10.1016/j.foodchem.2015.10.139

[2] Fabbri, A. D. T., Crosby, G. A. (2016). A review of the impact of preparation and cooking on the nutritional quality of vegetables and legumes. International Journal of Gastronomy and Food Science, 3, 2-11. doi: 10.1016/j.ijgfs.2015.11.001

[3] Nemeth, K., Piskula, M. K. (2007). Food Content, Processing, Absorption and Metabolism of Onion Flavonoids. Critical Reviews in Food Science and Nutrition, 47 (4), 397-409. doi: 10.1080/10408390600846291

[4] Antonia Murcia, M., Jimenez, A. M., Martinez-Tome, M. (2009). Vegetables antioxidant losses during industrial processing and refrigerated storage. Food Research International, 42 (8), 1046-1052. doi: 10.1016/j.foodres.2009.04.012

[5] Lin, D., Zhao, Y. (2007). Innovations in the development and application of edible coatings for fresh and minimally processed fruits and vegetables. Comprehensive Reviews in Food Science and Food Safety, 6 (3), 60-75. doi: 10.1111/j.1541-4337.2007.00018.x

[6] Barbosa, C., Alves, M. R., Rocha, S., Oliveira, M. B. P. P. (2016). Modified atmosphere packaging of precooked vegetables: Effect on physicochemical properties and sensory quality. Food Chemistry, 194, 391-398. doi: 10.1016/j.foodchem.2015.07.147

[7] Faour-Klingbeil, D., Todd, E. C. D., Kuri, V. (2016). Microbiological quality of ready-to-eat fresh vegetables and their link to food safety environment and handling practices in restaurants. LWT - Food Science and Technology, 74, 224-233. doi: 10.1016/j.lwt.2016.07.051

[8] Sanchez, C., Baranda, A. B., Martinez de Maranon, I. (2014). The effect of High Pressure and High Temperature processing on carotenoids and chlorophylls content in somevegetables. Food Chemistry, 163, 37-45. doi: 10.1016/j.foodchem.2014.04.041

[9] Drissner, D., Zuercher, U. (2014). Safety of Food and Beverages: Fruits and Vegetables. Encyclopedia of Food Safety, 3, 253-259. doi: 10.1016/B978-0-12-378612-8.00280-8

[10] Deynichenko, G., Tereshkin, O., Gorelkov, D., Dmitrevskyi, D. (2013). Stabilization of quality cleaning onion innovative way. Recent Journal, 14 (4 (40)), 246-250.

[11] Tereshkin, O. G., Gorelkov, D. V., Dmitrevskyi, D. V. (2016). Theoretical modeling of the heat treatment process vegetables during their peeling. Technology audit and production reserves, 1 (1 (27)), 57-65. doi: $10.15587 / 2312-8372.2016 .58826$

[12] GOST 28561-90. Produkty pererabotki plodov i ovoshchey. Metody opredeleniya suhih veshchestv ili vlagi (2011). Moscow: Standartinform, 11.

[13] Tereshkin, O. G., Gorelkov, D. V., Dmitrevskyi, D. V. (2013). Doslidzhennia parametriv kombinovanoho protsesu ochyshchennia tsybuli ripchastoi. Prohresyvni tekhnika ta tekhnolohii kharchovykh vyrobnytstv, restorannoho hospodarstva i torhivli, 1 (1), 159-165. 